\title{
Atmospheric dispersion of airborne pollen evidenced by near-surface and columnar measurements in Barcelona, Spain
}

\author{
Michaël Sicard*a,b, Rebeca Izquierdo ${ }^{\mathrm{c}}$, Oriol Jorba ${ }^{\mathrm{d}}$, Marta Alarcón ${ }^{\mathrm{c}}$, Jordina Belmonte ${ }^{\mathrm{e}, \mathrm{f}}$, Adolfo \\ Comerón $^{\mathrm{a}}$, Concepción De Linares ${ }^{\mathrm{e}, \mathrm{f}}$, José Maria Baldasano ${ }^{\mathrm{d}, \mathrm{g}}$

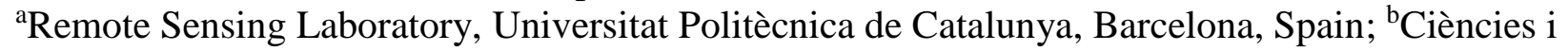 \\ Tecnologies de l'Espai - Centre de Recerca de l'Aeronàutica i de l'Espai / Institut d'Estudis Espacials \\ de Catalunya (CTE-CRAE / IEEC), Universitat Politècnica de Catalunya, Barcelona, Spain; \\ ${ }^{\mathrm{C}}$ Departament de Física, Universitat Politècnica de Catalunya (UPC), c/Urgell 187, 08036 Barcelona, \\ Spain; ${ }^{\mathrm{d} E a r t h}$ Sciences Department, Barcelona Supercomputing Center - Centro Nacional de \\ Supercomputación, Barcelona, Spain; ${ }^{~}$ Departament de Biologia Animal, Biologia Vegetal i \\ Ecologia, Universitat Autònoma de Barcelona (UAB). Edifici C, 08193 Bellaterra, Spain; ${ }^{\text {IInstitut de }}$ \\ Ciencia i Tecnología Ambientals (ICTA), Universitat Autònoma de Barcelona (UAB). Edifici Z, \\ 08193 Bellaterra, Spain; ${ }^{\mathrm{g} E n v i r o n m e n t a l}$ Modeling Laboratory, Technical University of Catalonia, \\ Barcelona, Spain
}

\begin{abstract}
Hourly measurements of pollen near-surface concentration and lidar-derived profiles of particle backscatter coefficients and of volume and particle depolarization ratios during a 5-day pollination event observed in Barcelona, Spain, between 27 - 31 March, 2015, are presented. Maximum hourly pollen concentrations of 4700 and $1200 \mathrm{~m}^{-3} \mathrm{~h}^{-1}$ were found for Platanus and Pinus, respectively, which represented together more than $80 \%$ of the total pollen. Everyday a clear diurnal cycle caused by the vertical transport of the airborne pollen was visible on the lidar-derived profiles of the backscatter coefficient with maxima usually reached between 12 and 15 UT. A method based on the lidar polarization capabilities was used to retrieve the contribution of the pollen to the total signal. On average the diurnal (9-17 UT) pollen aerosol optical depth (AOD) was 0.05 which represented $29 \%$ of the total AOD, the volume and particle depolarization ratios in the pollen plume were 0.08 and 0.14 , respectively, and the diurnal mean of the height of the pollen plume was found at $1.24 \mathrm{~km}$.

The dispersion of the Platanus and Pinus in the atmosphere was simulated with the Nonhydrostatic Multiscale Meteorological Model on the B grid at the Barcelona Supercomputing Center with a newly developed Chemical Transport Model (NMMB/BSC-CTM). Model near-surface daily concentrations were compared to our observations at two sites: in Barcelona and Bellaterra (12 km NE of Barcelona). Model hourly concentrations were compared to our observations in Barcelona.
\end{abstract}

Keywords: airborne pollen, near-surface concentration, columnar dispersion, lidar, local scale simulation

\section{INTRODUCTION}

Atmospheric pollen, a biogenic particle, commonly causes allergenic reactions when inhaled. Many people in European megacities suffer from allergies linked to the presence of atmospheric pollen. In the industrialized countries of central and northern Europe, up to $15 \%$ of the population is sensitive to pollen allergens ${ }^{[1][2]}$.

Pollen is produced by plants, flowers, trees, shrubs, etc. and is particularly harmful for humans in large cities close to woods and forests and/or with a significant quantity of ornamental trees and parks. In Europe the most common types of pollen are Ambrosia, Alnus, Artemisia, Betula, Corylus, Chenopodiaceae, Cupressaceae/Taxaceae, Olea, Platanus,

*msicard@tsc.upc.edu; phone 34 934011065; fax 34 934017200; http://www.tsc.upc.edu/rslab/Optical Remote Sensing/Welcome

Michaël Sicard; Rebeca Izquierdo; Oriol Jorba; Marta Alarcón; Jordina Belmonte; Adolfo Comerón; Concepción De Linares; José Maria Baldasano. "Atmospheric dispersion of airborne pollen evidenced by near-surface and columnar measurements in Barcelona, Spain". Proc. SPIE 10001, Remote Sensing of Clouds and the Atmosphere XXI, 100010L (19 October 2016), Adolfo Comerón; Evgueni I. Kassianov; Klaus Schäfer, Editor(s). DOI: 10.1117/12.2244517 
Poaceae, Quercus, and Urtica/Parietaria (Skjøth et al., 2013). Although their concentration is monitored daily at ground level by aerobiological networks ${ }^{[3][4]}$, very little is known on their vertical distribution and their long/short-range transport ${ }^{[5]}$.

In the Mediterranean city of Barcelona, Spain, the most abundant pollen taxa are Quercus (27.4\%of the total pollen), Pinus, Platanus, Cupressaceae, Olea, Urticaceae, Poaceae, Chenopodiaceae, Plantago, Moraceae, Fraxinus, Castanea, and Populus (1\%) according to the Aerobiological Network of Catalonia (http://lap.uab.cat/aerobiologia) and based on pollen concentrations measured in the period 1994-2015. In this contribution we relate for the first time in Barcelona, Spain, (i) pollen near-surface and columnar measurements, as well as (ii) pollen near-surface measurements and modelling of its dispersion in the atmosphere. The study is based on a recent 5-day pollination event that occurred in Barcelona between 27 and 31 March, 2015.

\section{INSTRUMENTATION AND MODELLING}

Pollen grain concentration was measured by the Aerobiological Network of Catalonia in the city centre of Barcelona $\left(2.165^{\circ} \mathrm{E}, 41.394^{\circ} \mathrm{N}, 67 \mathrm{~m}\right.$ a.s.1.) and in Bellaterra $\left(2.108^{\circ} \mathrm{E}, 41.501^{\circ} \mathrm{N}, 245 \mathrm{~m}\right.$ a.s.1.), a city situated approximately 14 $\mathrm{km}$ to the northwest of the Barcelona city centre. Profiles of particle backscatter coefficient and linear volume and particle depolarization ratios were acquired at the Remote Sensing Lab (RSLab) in the North Campus of the Universitat Politècnica de Catalunya $\left(2.112^{\circ} \mathrm{E}, 41.389^{\circ} \mathrm{N}, 115 \mathrm{~m}\right.$ a.s.1.), approximately $4.4 \mathrm{~km}$ to the west of the Barcelona pollen sampling instrumentation. Meteorological data (pressure, temperature, relative humidity, wind speed and direction) were recorded near the RSLab.

\subsection{Pollen near-surface sampling instrumentation}

Pollen samples are obtained using volumetric suction pollen-spore trap based on the impact principle ${ }^{[6]}$, the standardized method in European aerobiological networks. The Hirst sampler (Figure 1a) is calibrated to handle a flow of 10 litre of air per minute, thus matching the human breathing rate. Pollen grains are impacted on a cylindrical drum covered by a melinex film coated with a 2-\% silicon solution as trapping surface. The Melinex film is made of 7 bands, each one being 48-mm long and corresponding to 24 hours. The drum is changed weekly and the exposed tape is cut into seven pieces, each one corresponding to one day. Pollen grains are counted under light microscope, at 600X magnification. Daily average pollen counts are obtained following the standardized Spanish method ${ }^{[7]}$, consisting in running four longitudinal sweeps along the $24 \mathrm{~h}$ slide for daily data, identifying and counting each pollen type found. To obtain the hourly concentrations, twenty-four continuous transversal sweeps separated every $2 \mathrm{~mm}$ along the daily-sample slide are analyzed, since the drum rotates at a speed of $2 \mathrm{~mm}$ per hour. Daily and intra-diurnal (hourly) pollen and spore concentrations are obtained converting the pollen and spore counts into particles per cubic meter of air, taking into account the proportion of the sample surface analyzed and the air intake of the Hirst pollen trap $\left(101 \mathrm{~min}^{-1}\right)$.
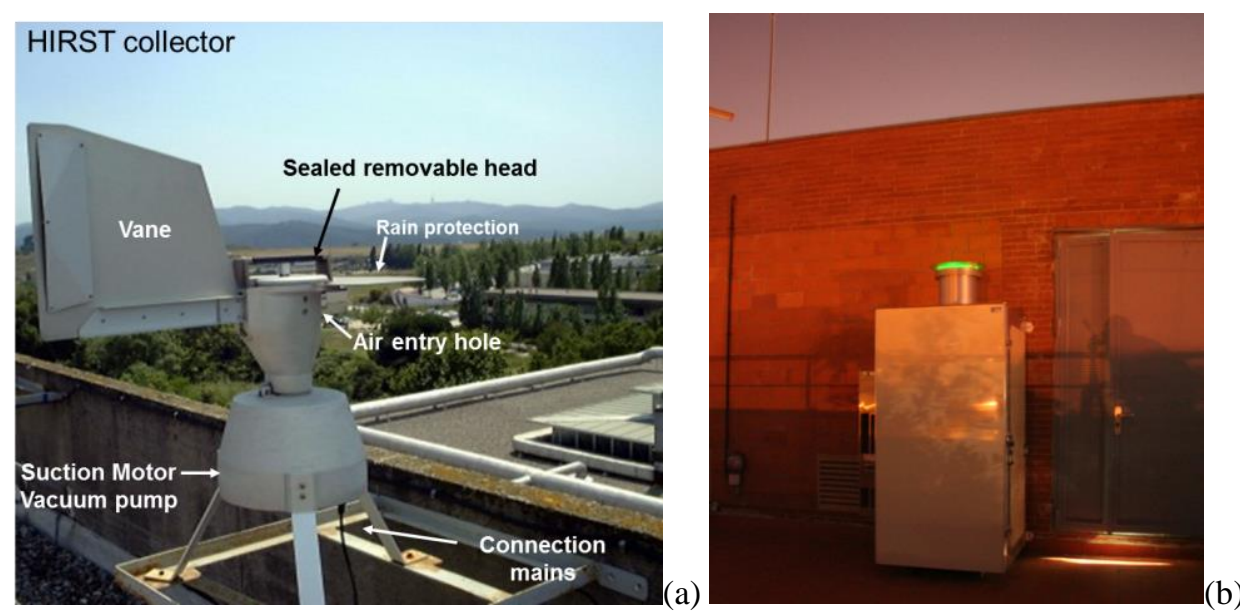

Figure 1. (a) Picture of a Hirst collector used to collect the pollen samples; (b) Picture at dusk of the Barcelona Micro Pulse Lidar system. 


\subsection{Pollen columnar measurements}

The profiles of the particle backscatter coefficient and the volume and particle depolarization ratios were measured with the Barcelona Micro Pulse Lidar (MPL) system, model MPL-4B (Figure 1b). The system is part of the MPLNET (Micro Pulse Lidar Network, http://mplnet.gsfc.nasa.gov/) network. The MPL system is a compact, eye-safe lidar designed for full-time unattended operation ${ }^{[8][9]}$. It uses a pulsed solid-state laser emitting low laser pulse energy $(\sim 6 \mu \mathrm{J})$ at a high pulse rate $(2500 \mathrm{~Hz})$ and a co-axial "transceiver" design with a telescope shared by both transmit and receive optics. The Barcelona MPL optical layout uses an actively controlled liquid crystal retarder which makes the system capable to conduct polarization-sensitive measurements by alternating between two retardation states ${ }^{[9]}$. The signals acquired in each of these states are recorded separately and called "co-polar" and "cross-polar". In nominal operation the raw temporal and vertical resolutions are $30 \mathrm{~s}$ and $15 \mathrm{~m}$, respectively. The total lidar signal, $\mathrm{P}$, as a function of the altitude, $\mathrm{z}$, is reconstructed from the "co-polar", $P_{c o}$, and "cross-polar", $P_{\mathrm{cr}}$, signals as ${ }^{[9]}$ :

$$
P(z)=P_{c o}(z)+2 P_{c r}(z)
$$

The particle backscatter coefficient, $\beta^{p}$, was retrieved with the two-component elastic algorithm with a constant lidar ratio of $50 \mathrm{sr}$.

By adapting the notations of Flynn et al. (2007) ${ }^{[9]}$ to ours one can formulate the linear volume depolarization ratio, $\delta^{\mathrm{V}}$, for the MPL system as:

$$
\delta^{V}(z)=\frac{P_{c r}(z)}{P_{c o}(z)+P_{c r}(z)}
$$

The linear particle depolarization ratio, $\delta^{\mathrm{p}}$, can then be determined by [10]:

$$
\delta^{p}(z)=\frac{\left[1+\delta^{m}\right] \delta^{V}(z) R(z)-\left[1+\delta^{V}(z)\right] \delta^{m}}{\left[1+\delta^{m}\right] R(z)-\left[1+\delta^{V}(z)\right]}
$$

where $\delta^{\mathrm{m}}$ is the molecular depolarization ratio and $\mathrm{R}$ is the backscatter ratio which is defined as:

$$
\mathrm{R}(z)=\frac{\beta^{m}(z)+\beta^{p}(z)}{\beta^{m}(z)}
$$

where $\beta^{\mathrm{m}}$ and $\beta^{\mathrm{p}}$ denote the molecular and particle backscatter coefficient, respectively, of the total lidar signal. For the Barcelona MPL lidar, a value of $\delta^{\mathrm{m}}=0.00363$ was used ${ }^{[11]}$.

Finally we also calculated the vertical height, $\mathrm{h}_{\mathrm{pol}}$, up to which the pollen plume extends. As it is shown in [11], the pollen plume is characterized during the whole pollination event by a near-constant or slightly decreasing profile of $\beta^{\mathrm{p}}$. From this aspect the structure of the pollen plume is much simpler than the ABL structure usually found in Barcelona ${ }^{[18}$ and allows us to use a simple threshold method ${ }^{[11]}$. To further compare surface concentrations to lidar-derived products, we also define column-integrated lidar-derived parameters such as $\overline{\delta^{V}}$ and $\overline{\delta^{p}}$, obtained by averaging the profile of $\delta^{V}$ and $\delta^{p}$ from the ground up to $\mathrm{h}_{\mathrm{pol}}$, thereby limiting the averaging to the pollen plume.

\subsection{Pollen dispersion modelling}

The dispersion of the airborne pollen in the atmosphere was modelled with the NMMB/BSC-CTM model (Nonhydrostatic Multiscale Meteorological Model on the B grid (NMMB) from the Barcelona Supercomputing Center (BSC) with a newly developed Chemical Transport $\operatorname{Model}(\mathrm{CTM})$ ). It is the online air quality forecast system developed at $\mathrm{BSC}^{[12][13]}$. Meteorology and transport schemes are the ones from [14]. For the pollen simulations, the output of the model were configured as follows:

- Horizontal Resolution: $1 \mathrm{~km}$ x $1 \mathrm{~km}$

- Vertical Resolution: 48 hybrid sigma-pressure

- Top Atmosphere: $50 \mathrm{hPa}$

- Time step: $2 \mathrm{~s}$ 
The two pollen types largely predominant during the pollination event were Pinus and Platanus (see Section 3). For this reason the aerosol scheme was set to bulk Pinus and Platanus aerosols. The main parameters were taken from the literature and local and regional databases and are reported in Table 1.

Table 1. Pollen parametrization used in the aerosol scheme.

\begin{tabular}{|c|c|c|c|c|}
\hline \multirow[b]{3}{*}{$\begin{array}{l}\text { Geographical } \\
\text { distribution }\end{array}$} & \multicolumn{2}{|r|}{ Pinus } & \multicolumn{2}{|r|}{ Platanus } \\
\hline & Value & Source & Value & Source \\
\hline & - & $\begin{array}{l}\text { Cartography of } \\
\text { habitats of Catalonia }\end{array}$ & - & $\begin{array}{l}\text { Barcelona's City Hall } \\
\text { Open Data Service }\end{array}$ \\
\hline $\begin{array}{l}\text { Tree density } \\
\text { (tree/ha) }\end{array}$ & 650 & $\begin{array}{l}\text { Forest Inventory of } \\
\text { Catalonia }\end{array}$ & & \\
\hline $\begin{array}{l}\text { Emission factor } \\
\text { (g/day/tree) }\end{array}$ & 81 & Williams et al. (2009) & 2.48 & Brichi et al. (2000) \\
\hline $\begin{array}{l}\text { Grain diameter } \\
(\mu \mathrm{m})\end{array}$ & 59 & Zhang et al. (2014) & 19 & Zhang et al. (2014) \\
\hline $\begin{array}{l}\text { Grain density } \\
\left(\mathrm{kg} / \mathrm{m}^{3}\right)\end{array}$ & 560 & $\begin{array}{l}\text { Jackson and Liford } \\
\text { (1999) }\end{array}$ & 920 & Zhang et al. (2014) \\
\hline
\end{tabular}

\section{EVIDENCE OF POLLEN RELEASE AND DISPERSION}

In addition to pollen daily concentration measurements which are performed routinely at the stations of the Aerobiological Network of Catalonia, hourly concentrations were also retrieved for the period of interest between 27 and 31 March, 2015. Figure 2 shows the time series of 1) the total pollen, Pinus and Platanus concentrations and 2) the volume depolarization ratio as a function of height. One sees that Platanus and also Pinus are the two dominant species. Indeed together they represent more than $80 \%$ of the total pollen concentration ${ }^{[11]}$. With the exception of $31 \mathrm{March}$, the pollen number concentration at ground level follows a clear diurnal cycle. On $31 \mathrm{March}$, no clear difference is observed between day and night. Platanus and Pinus concentration reaches maximum peaks of $\sim 4700 \mathrm{~m}^{-3}$ on 31 March and 1200 $\mathrm{m}^{-3}$ on 30 March, respectively. Maximum peaks of the total pollen concentration higher than 5000 and $6000 \mathrm{~m}^{-3}$ are reached on 30 and $31 \mathrm{March}$, respectively. They are associated with absolute peaks of Platanus and relative peaks of Pinus. Interestingly a release cycle is visible each day: the diurnal variation is marked with several relative peaks along the day that are usually distant in time by 2 to $4 \mathrm{~h}$. Platanus and Pinus peaks are not necessarily correlated. The fact that Platanus variations are shaper than Pinus ones may be explained by the size difference between both pollen types: while Platanus longest diameter (on the polar axis) varies between 21 and $28 \mu \mathrm{m}$, it varies between 60 and $74 \mu \mathrm{m}$ for Pinus (https://www.polleninfo.org/AT/en/allergy-infos/aerobiologics/pollen-atlas.html?letter=P). Pollen size is known to be a factor affecting not only pollen release but also pollen settlement to the ground (McCartney, 1994).

The green color code volume depolarization ratio (Figure 2, bottom) indicates values of $\delta^{\mathrm{V}}$ near $0.02-0.03$. It is the usual value of $\delta^{\mathrm{V}}$ for background, local aerosols near the surface in Barcelona. Everyday around 08 UT a plume with $\delta^{\mathrm{V}}$ $>0.08$ (yellowish) appears, raises up to $1.0-1.7 \mathrm{~km}$ in a few hours and starts decreasing before 16 UT at a lesser rate than it raised. This diurnal pattern of $\delta^{\mathrm{V}}$ is observed on each single day of the pollination event. On the first four days values of $\delta^{\mathrm{V}}$ larger than 0.08 are no longer detected after $18-20 \mathrm{UT}$. Toward the end of the event on 30 and 31 March when the pollen concentrations were the highest, values of $\delta^{\mathrm{V}}>0.08$ are still detected until 21-24 UT. The highest values of $\delta^{\mathrm{V}}$ are detected on 30 March and are of the order of 0.22 . This maximum value is higher than the peak value of 0.15 observed by [16] for Pinus and Quercus pollen in South Korea and lower than $\delta^{\mathrm{V}}=0.30$ measured by [17] for birch pollen plumes from the boreal forest of Alaska.

To gain an insight into the meteorological conditions yielding to pollen release we have plotted together the total pollen concentration and the meteorological parameters as a function of time in Figure 3. One sees a clear positive correlation between the total pollen concentration and temperature and wind speed and less pronounced negative correlation between concentration and relative humidity. The correlation coefficient between the daily mean temperature (wind speed) and the daily total pollen concentration is $0.95(0.82)$, indicating a strong dependence of pollen release upon temperature and wind speed. The correlation coefficient between the daily mean relative humidity and the daily total pollen concentration, -0.18 , is negative and much lower (in absolute value) than the one for temperature. 
To further investigate the relationship between surface concentration and columnar properties we plot in Figure 4 the volume depolarization profile as a function of time and height together with the concentrations of total pollen, Platanus

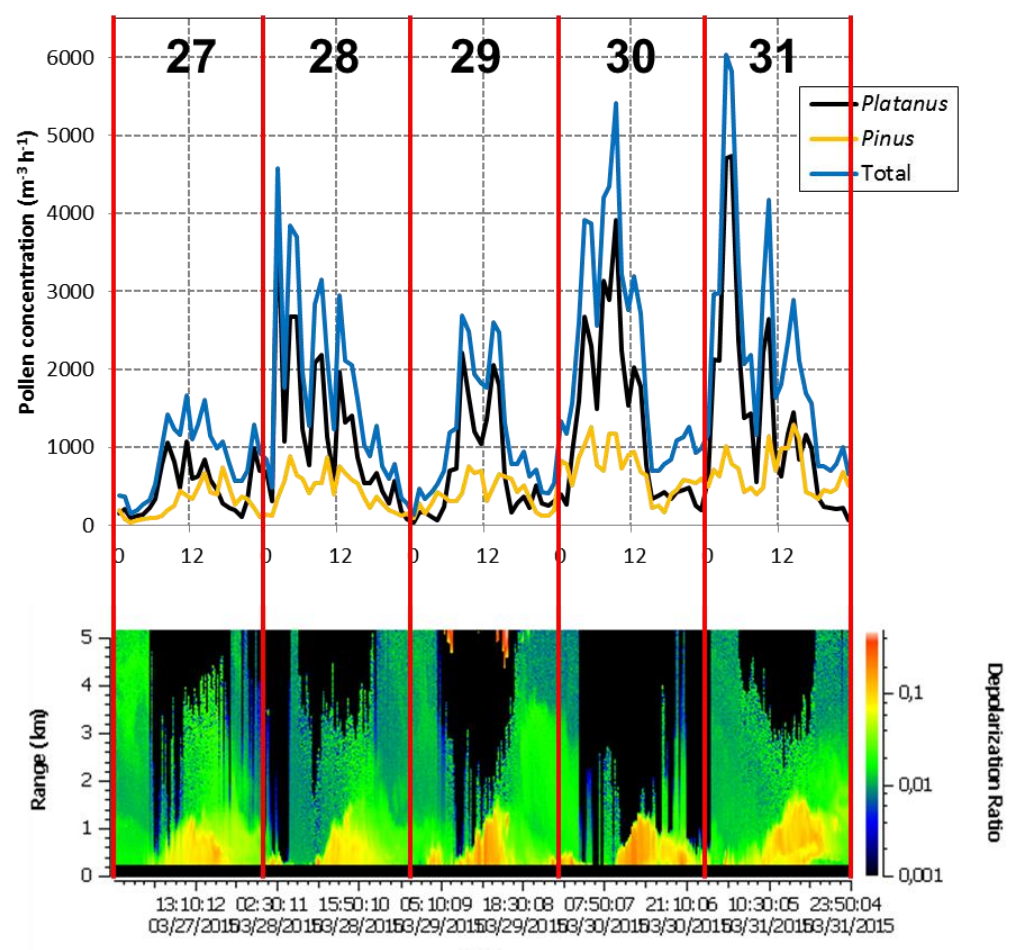

Time

Figure 2. (top) Hourly airborne pollen concentration measured at the surface; (bottom) volume depolarization profile as a function of time and height. The bottom plot has a five-minute time resolution.

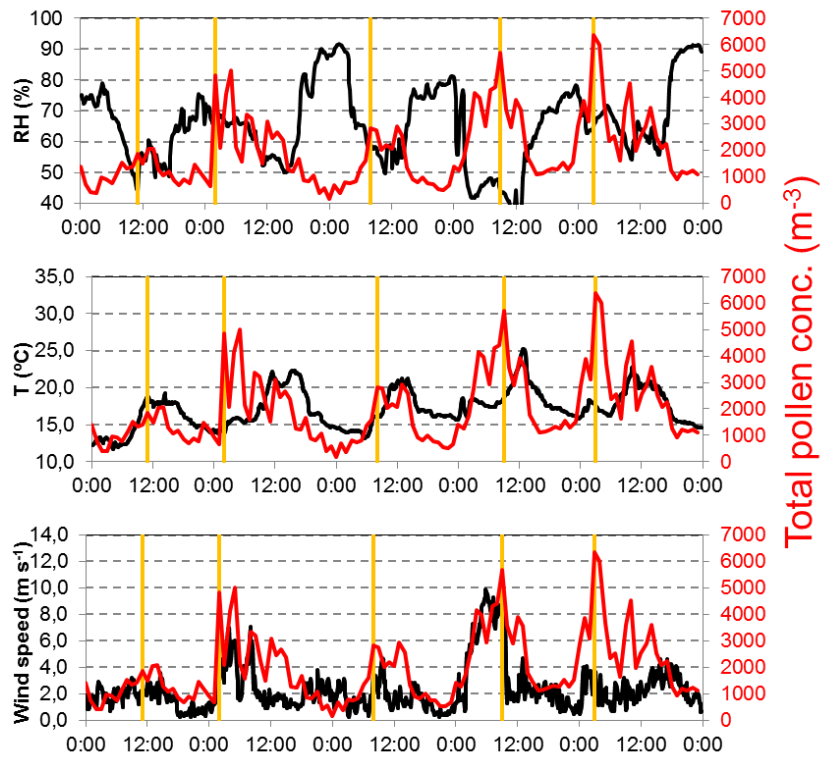

Figure 3. Total pollen concentration (red, right axis) superimposed on (black, left axis) (top) relative humidity, (center) temperature and (bottom) wind speed. The vertical orange line indicate for each day the time with the highest concentration value. 
and Pinus. For each day we also report in Figure 4 the correlation coefficient between hourly surface concentration and $\overline{\delta^{V}}$. For both pollen types, Platanus and Pinus, the release (concentration) and dispersion $\left(\delta^{\mathrm{V}}\right)$ are well correlated on 27 and 29 March. The highest correlation coefficients are reached on those days. For 28, 30 and 31 March, a nocturnal surface activity is visible on the concentration while $\delta^{\mathrm{V}}$ remains low. The nocturnal pollen activity seems to be linked to strong wind speeds (see Figure 3). The highest correlation coefficients are in general found for the total pollen, which suggests that the relationship between surface concentration and columnar $\delta^{\mathrm{V}}$ does not depend on a single pollen type but on the whole.
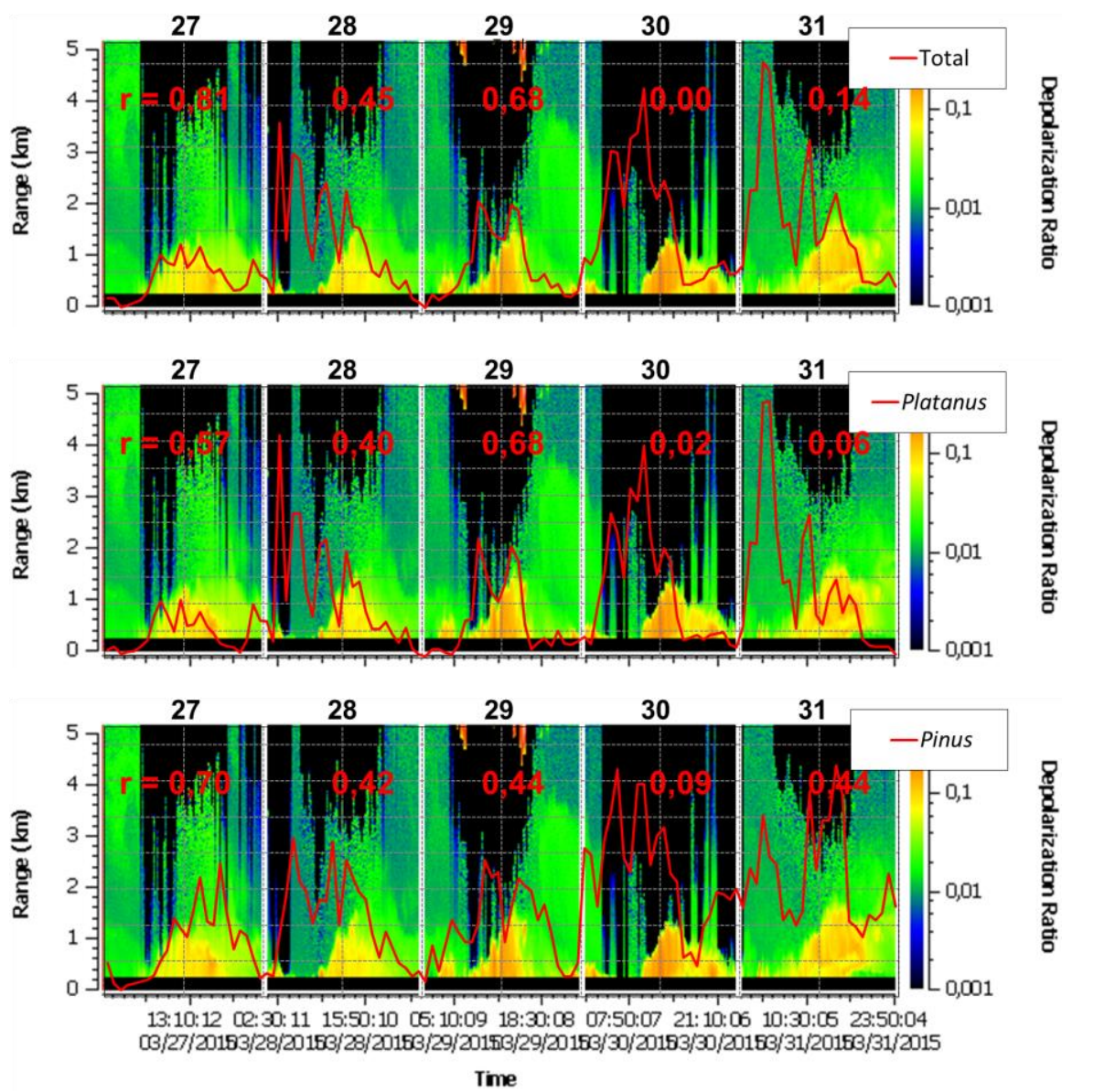

Figure 4. Volume depolarization profile as a function of time and height on which the concentrations of (top) total pollen, (center) Platanus and (bottom) Pinus have been superimposed. On each plot and for each day the correlation coefficient, $r$, calculated between hourly concentrations and hourly $\overline{\delta^{V}}$ is reported in red.

\section{MODELLING OF THE POLLEN ATMOSPHERIC DISPERSION}

This section presents the results of the very first simulation of pollen dispersion performed in the Catalonian region. The pollen (Pinus and Platanus) parametrization used in NMMB/BSC-CTM can be found in Table 1. By combining the different sources of geographical distribution and tree density maps showing the tree location and density were generated and are shown in Figure 5. The spatial distribution of Pinus and Platanus trees was limited because of our sources themselves, respectively the Cartography of habitats of Catalonia and the Barcelona's City Hall Open Data Service. This limitation results in a spatial distribution of Pinus in a region around Barcelona not further than $50 \mathrm{~km}$ from the city center, and in a spatial distribution for Platanus strictly limited to the Barcelona metropolitan area (the distribution of Platanus trees outside of the city is not known). The pollen concentrations at ground level estimated by NMMB/BSC- 
CTM are first compared to the observations in terms of daily concentration at both Barcelona and Bellaterra (Figure 6) and then in terms of hourly concentration in Barcelona (Figure 7).
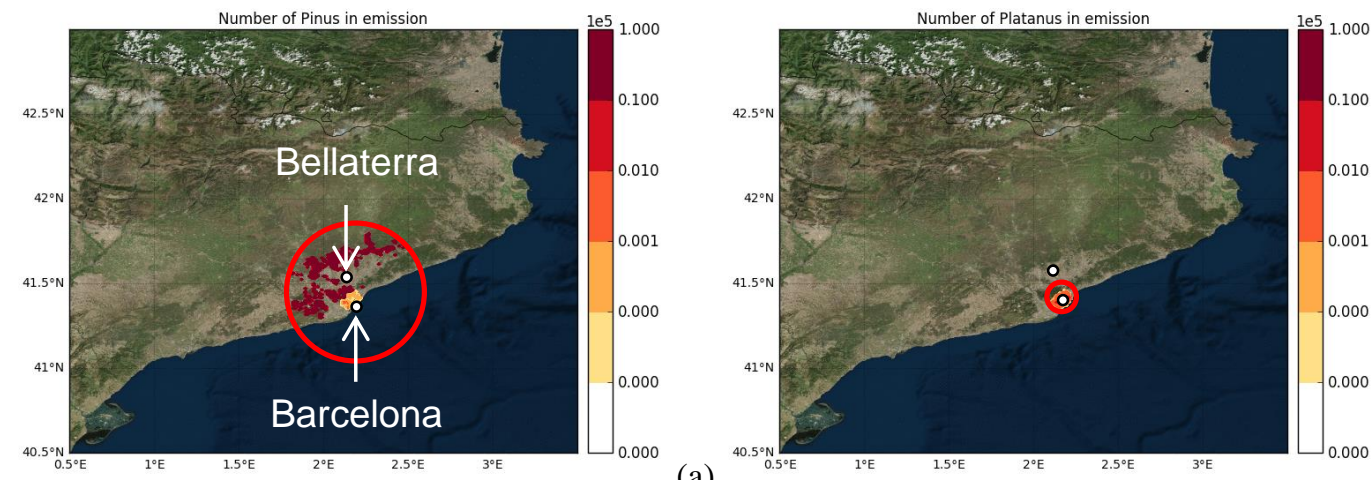

(a)

Figure 5. (a) Pinus and (b) Platanus geographical distribution and density. On each plot a circle of radius $50 \mathrm{~km}$ (Pinus) and 10 $\mathrm{km}$ (Platanus) centered on the Barcelona city center is represented.

Daily concentrations of Pinus are relatively well retrieved by NMMB-BSC/CTM as all points fall between the $1 / 3$ and 3/1 ratio lines (Figure 6). The concentration in Bellaterra seems a little overestimated while it seems underestimated in Barcelona. Explanation... Platanus concentration is clearly underestimated at both sites. It is partly due to two reasons: (i) the limitation mentioned earlier of the Platanus tree spatial distribution map used in emission and (ii) an underestimation of the emission factor $2.48 \mathrm{~g} /$ day/tree used. We are currently working on a better tuning of this parameter. Interestingly model and observed concentrations agree exceptionally well (differences less than $20 \%$ ) on the same day, 27 March, the day for which surface concentration and columnar $\delta^{\mathrm{V}}$ correlates the most $(r$-values $\geq 0.57)$.

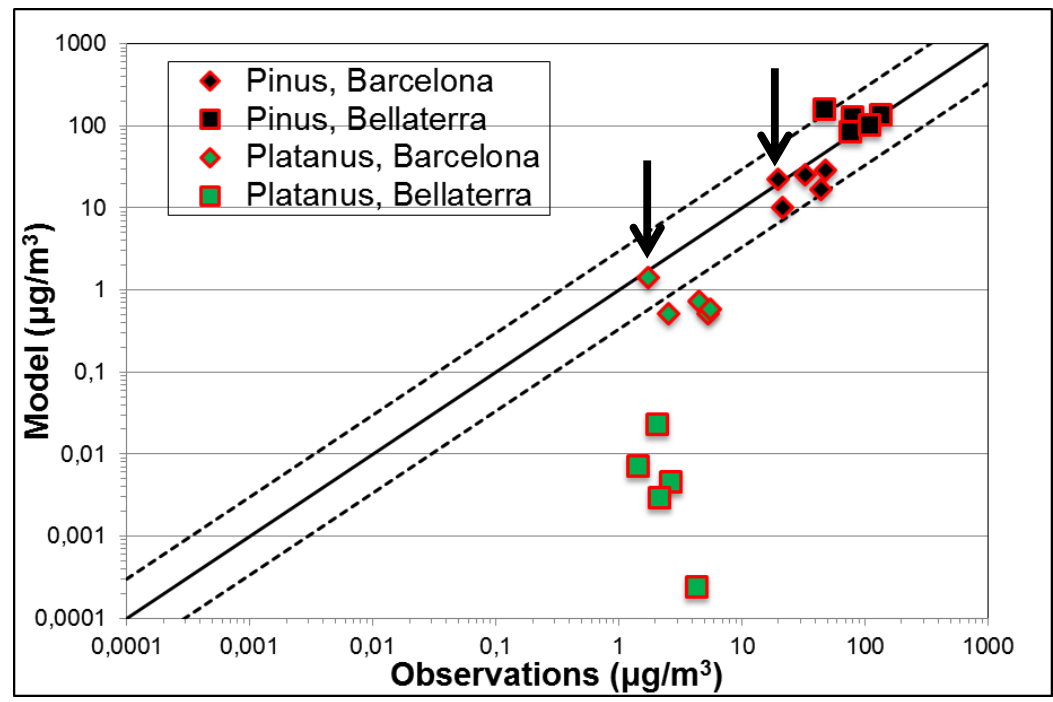

Figure 6. Model vs. observed daily concentration in Barcelona and Bellaterra for Pinus and Platanus during the five days of the pollination event period, 27-31 March, 2015. Dotted lines represent either 3/1 or 1/3 ratios. The two points of Barcelona corresponding to 27 March are indicated with a vertical arrow

The analysis of the hourly concentrations in Barcelona (Figure 7) gives a further insight into the model behaviour at fine temporal scale. For both types of pollen, we observe (Figure 7a and Figure $7 \mathrm{~b}$ ) that approximately half of the points fall within the 1/3-3/1 ratio lines and the other half below the 1/3 ratio lines, suggesting a general tendency of the model to underestimate the concentration of pollen. We have plotted separately the nighttime and daytime concentration (not shown) and roughly found the same spreading of the points, suggesting that the performance of the model are independent of the period of the day. This result is reinforced by Figure $7 \mathrm{c}$ and Figure $7 \mathrm{~d}$ which show agreements and disagreements between model and observations equally during daytime than during nighttime. In Figure 7a and Figure $7 \mathrm{~b}$ the points for 27 March are stressed by red dots in order to check if the good agreement found for the daily 
concentration was also true for the hourly ones and it appears that for the hourly concentrations the agreement is not as good. For Pinus roughly half of the points are overestimated (first half of the day, see Figure 7c) while the other half are underestimated (second half of the day). This result points out that on 27 March the good agreement found on the daily concentration is circumstancial, as it is not reproduced on the hourly concentrations. For Platanus on 27 March, the model estimates relatively well the nighttime concentration while it underestimates the diurnal ones.

The comparison of the temporal evolution of the model and observed hourly concentrations (Figure 7c and Figure 7d) allows to identify the periods of the event when model and observations agree the best. As expected from the analysis of the daily concentration, Platanus concentrations are largely underestimated by the model. Except on the first half of 27 March when the model overestimates the Pinus hourly concentration, the simualtions seem to have two main behaviors: they either underestimates the observed concentration (all the periods with a model concentration $<10 \mu \mathrm{g} / \mathrm{m}^{3}$ ) or they agree relatively well with the observations. Two periods show specially good agreements: the day of 28 March and the first half of 30 March. On both cases the strong increase of the concentration at the beginning of each period is related to
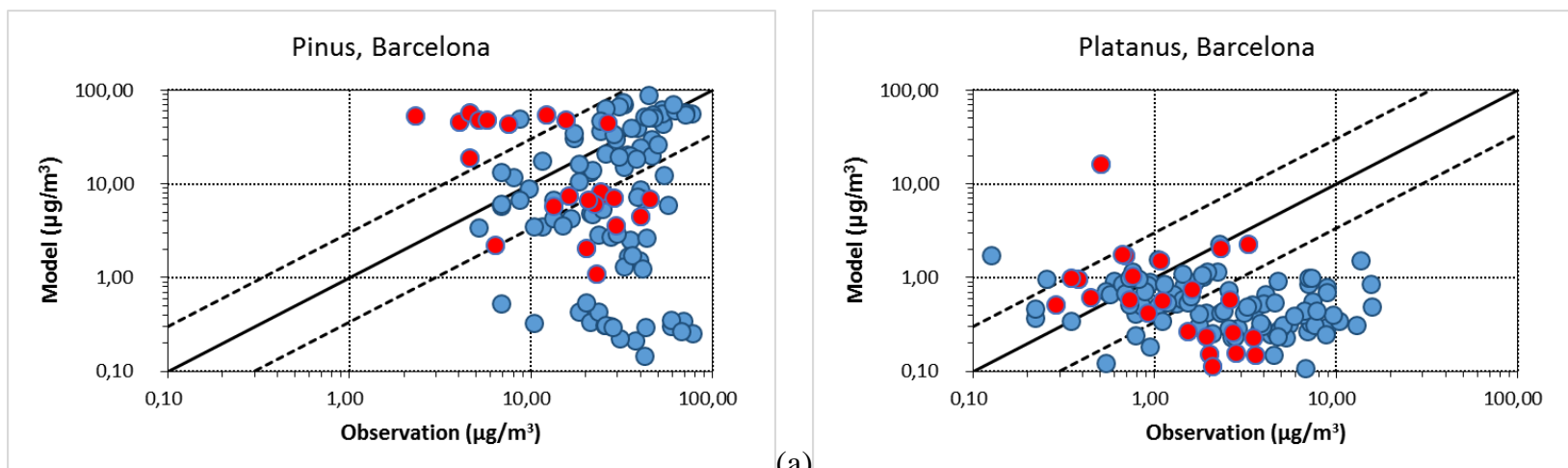

(a)
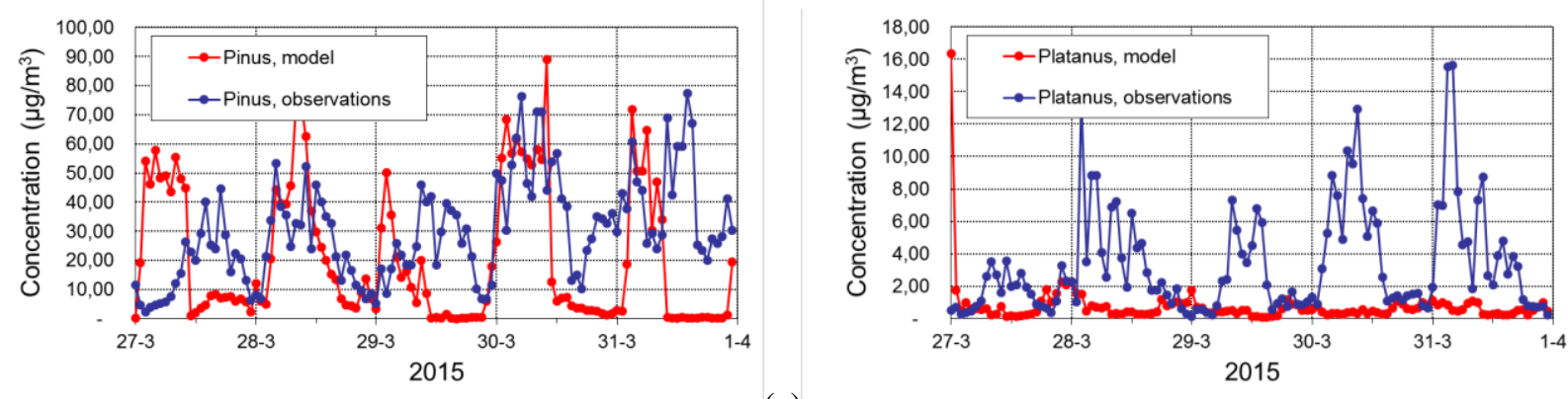

(c)

Figure 7. Model vs. observed hourly concentration in Barcelona for (a) Pinus and (b) Platanus during the five days of the pollination event period, 27-31 March, 2015. Dotted lines represent either 3/1 or 1/3 ratios. The red dots correspond to 27 March. Temporal evolution of both model and observed concentration of (c) Pinus and (d) Platanus.
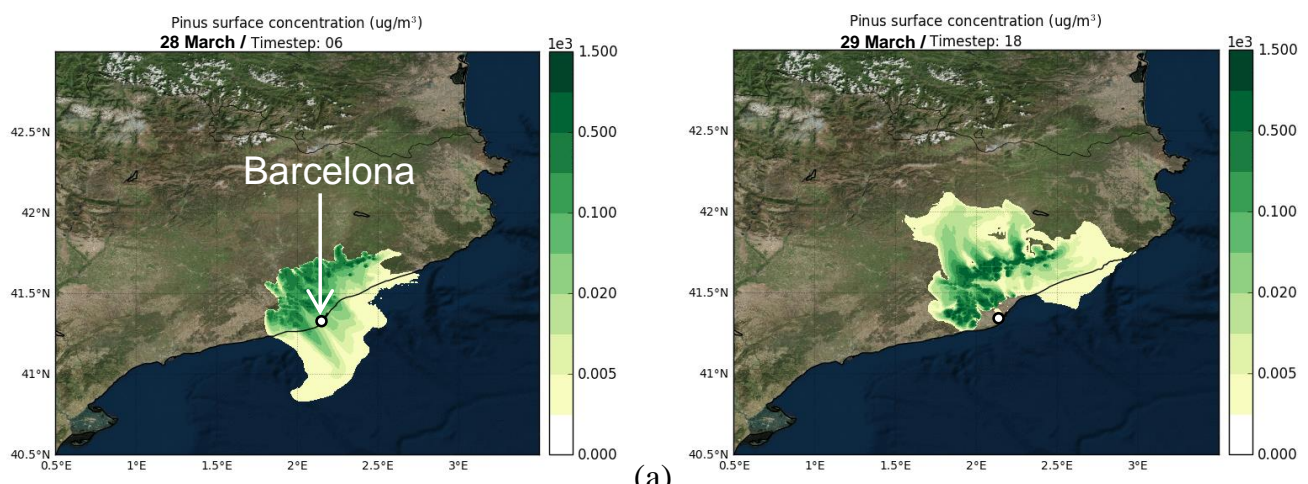

(a)

Figure 8. Pinus surface concentration (a) on 28 March at 06UT and (b) on 29 March at 18UT. 
strong nighttime winds (see Figure 3). This point reveals the importance of the meteorological scheme used by the meteorological model for the modelization of airborne pollen. To put the emphasis on that conclusion we extract from the hourly simulations the maps of the spatial distribution of Pinus concentration at ground level on 28 March at 06UT (good agreement, Figure 8a) and on 29 March at 18UT (bad agreement, Figure 8b). On 28 March at 06UT the predominant northwesterly winds are visible on the map. The progressive decrease of the concentration from dark green inland to light yellow over the sea reveals the importance as well, in addition to the meteorology, of the localization and the right quantification of the emission. Figure $8 \mathrm{~b}$ is a clear example that if the meteorology scheme is not reproducing the real conditions (here the model forecasts rather winds from south, i.e. driving the pollen plume away from the city center), then the model is unable to reproduce the right pollen concentration.

\section{CONCLUSIONS}

\section{ACKNOWLEDGMENTS}

Lidar data analysis were supported by the ACTRIS (Aerosols, Clouds, and Trace Gases Research Infrastructure Network) Research Infrastructure Project funded by the European Union's Horizon 2020 research and innovation programme under grant agreement n. 654169 and previously under grant agreement n. 262254 in the $7^{\text {th }}$ Framework Programme (FP7/2007-2013); by the Spanish Ministry of Economy and Competitivity (projects TEC2012-34575 and TEC2015-63832-P) and of Science and Innovation (project UNPC10-4E-442) and EFRD (European Fund for Regional Development); by the Department of Economy and Knowledge of the Catalan autonomous government (grant 2014 SGR 583). The authors also thank the Facultad de Física of the Universitat de Barcelona for providing the meteorological measurements.

\section{REFERENCES}

[1] WHO: World Health Report 2003: "A Vision for Global Health, Shaping the Future", World Health Organization (2003).

[2] Cecchi, L., "From pollen count to pollen potency: the molecular era of aerobiology", Eur. Respir. J. 42, 898900, doi:10.1183/09031936.00096413 (2013).

[3] Scheifinger, H., Belmonte, J., Buters, J., Celenk, S., Damialis, A., Dechamp, Ch., García-Mozo, H., Gehrig, R., Grewling, L., Halley, J. M., Hogda, K.-A., Jäger, S., Karatzas, K., Karlsen, S.-R., Koch, E., Pauling, A., Peel, R., Sikoparija, B., Smith, M., Galán-Soldevilla, C., Thibaudon, M., Vokou, D., and de Weger, L. A., "Monitoring, Modeling and forecasting of the Pollen Season", in: Allergenic Pollen. A review of the Production, Release, Distribution and Health Impacts, edited by: Sofiev, M. and Bergmann, K.-Ch., 127-158, doi:10.1007/978-94-007-4881-1, Springer (2013).

[4] Karatzas, K.D., Riga, M., and Smith, M., "Presentation and Dissemination of Pollen Information", in: Allergenic Pollen. A review of the Production, Release, Distribution and Health Impacts, edited by: Sofiev, M. and Bergmann, K.-Ch., 217-247, doi:10.1007/978-94-007-4881-1, Springer (2013).

[5] Sofiev, M., Belmonte, J., Gehrig, R., Izquierdo, R., Smith, M., Dahl, A., and Siljamo, P., "Airborne Pollen Transport, in: Allergenic Pollen. A review of the Production, Release, Distribution and Health Impacts", edited by: Sofiev, M. and Bergmann, K.-Ch., 127-158, doi:10.1007/978-94-007-4881-1, Springer (2013).

[6] Hirst, J.M., "An automatic volumetric spore trap", Ann. Appl. Biol. 39, 257-265 (1952).

[7] Galán Soldevilla, C., Cariñanos González, P., Alcázar Teno, P., and Domínguez Vilches, E., "Manual de Calidad y Gestión de la Red Española de Aerobiología", Servicio de Publicaciones, Universidad de Córdoba (2007).

[8] Campbell, J. R., Hlavka, D.L., Welton, E. J., Flynn, C. J., Turner, D. D., Spinhirne, J. D., Scott, V. S., and Hwang, I. H., "Full-time, eye-safe cloud and aerosol lidar observation at Atmospheric Radiation Measurement Program sites: instruments and data processing", J. Atmos. Ocean. Tech. 19, 431-442 (2002). 
[9] Flynn, C. J., Mendoza, A., Zheng, Y., and Mathur, S., "Novel polarization-sensitive micropulse lidar measurement technique", Optics Express 15(6), 2785-2790 (2007).

[10] Freudenthaler, V., Esselborn, M., Wiegner, M., Heese, B., Tesche, M., Ansmann, A., Muller, D., Althausen, D., Wirth, M., Fix, A., Ehret, G., Knippertz, P., Toledano, C., Gasteiger, J., Garhammar, M., and Seefeldner, M., "Depolarizationratio profiling at several wavelengths in pure Saharan dust during SAMUM 2006", Tellus B 61, 165-179, doi:10.1111/j.1600-0889.2008.00396.x (2009).

[11] Sicard, M., Izquierdo, R., Alarcón, M., Belmonte, J., Comerón, A., and Baldasano, J. M., "Near-surface and columnar measurements with a micro pulse lidar of atmospheric pollen in Barcelona, Spain", Atmos. Chem. Phys. 16, 6805-6821, doi:10.5194/acp-16-6805-2016 (2016).

[12] Pérez, C., Haustein, K., Janjic, Z., Jorba, O., Huneeus, N., Baldasano, J. M., Black, T., Basart, S., Nickovic, S., and Miller, R.L., "Atmospheric dust modeling from meso to global scales with the online NMMB/BSC-Dust model - Part 1: Model description, annual simulations and evaluation", Atmospheric Chemistry and Physics 11, 13001-13027 (2011).

[13] Jorba, O., Dabdub, D., Blaszczak-Boxe, C., Pérez, C., Janjic, Z., Baldasano, J. M., Spada, M., Badia, A., and Gonçalves, M., "Potential significance of photoexcited NO2 on global air quality with the NMMB/BSC chemical transport model", Journal of Geophysical Research 117(D13301), 1-16 (2012).

[14] Janjic, Z., and R.L. Gall, "Scientific documentation of the NCEP nonhydrostatic multiscale model on the B grid (NMMB). Part 1 Dynamics", NCAR Technical Note NCAR/TN-489+STR, doi: 10.5065/D6WH2MZX (2012).

[15] McCartney, H. A., "Dispersal of spores and pollen from crops", Grana 33(2), 76-80, doi: 10.1080/00173139409427835 (1994).

[16] Noh, Y. M., Lee, H., Müller, D., Lee, K., Shin, D., Shin, S., Choi, T. J., Choi, Y. J., and Kim, K. R., "Investigation of the diurnal pattern of the vertical distribution of pollen in the lower troposphere using LIDAR", Atmos. Chem. Phys. 13, 7619 - 7629, doi:10.5194/acp-13-7619-2013 (2013).

[17] Sassen, K., "Boreal tree pollen sensed by polarization lidar: depolarizing biogenic chaff", Geophys. Res. Lett. 35, L18810, doi: 10.1029/2008GL035085 (2008).

[18] Sicard, M., Pérez, C., Rocadenbosch, F., Baldasano, J. M., and García-Vizcaino, D., "Mixed-layer depth determination in the Barcelona coastal area from regular lidar measurements: methods, results and limitations", Bound.-Lay. Meteorol. 119, 135-157 (2006). 